Bangladesh J. Bot. 43(3): 337-344, 2014 (December)

\title{
AGRO-MORPHOLOGICAL DIVERSITY IN WILD RICE ACCESSIONS OF EASTERN INDO-GANGETIC REGION OF INDIA
}

\author{
SK Chouhan, AK Singh, Aparajita Singh, SP Singh, NK Singh ${ }^{1}$ and PK SingH ${ }^{*}$ \\ Department of Genetics and Plant Breeding, Institute of Agricultural Sciences, \\ Banaras Hindu University, Varanasi-221005, India
}

Key words: Collection, Genetic diversity, Eastern Indo-Gangetic region, Wild accession

\begin{abstract}
Thirty five wild rice germplasm accessions collected from natural habitat of Eastern Indo-Gangetic region of India were evaluated to estimate their extent of genetic variability, agro-morphological divergence and relationship among themselves for 14 traits. The accessions showed significant genotypic coefficient of variation for all traits analyzed. The accessions were clustered into six groups, the cluster III contained the highest 12 accessions, and clusters I and IV comprised 11 and 7 accessions, respectively; while cluster II and VI have two accessions each, and clusters V was monogenotypic. The maximum intra-cluster distance was observed in cluster VI followed by clusters IV and II while in inter-cluster distance was observed between clusters V and VI followed by clusters II and V indicates wider genetic diversity between germplasm accessions. High heritability coupled with high genetic advance as per cent of mean was found in the traits filled grains per panicle, total number of grains per panicle and grain yield per plant. The result suggested that these accessions are valuable resource and can be utilized for yield and yield traits besides disease and pest. Therefore, these accessions should be conserved to utilize in transgressive segregation breeding programme of cultivated indica rice.
\end{abstract}

\section{Introduction}

The genus Oryza consists 22 wild and two cultivated species Oryza sativa and O. glaberrima, belonging to the family Poaceae. Wild rices are valuable repository of useful allelic variation for crop improvement, though it is often difficult to transfer these genes into background of the cultivated rice. It provided many valuable traits such as disease and pest resistance and cytoplasmic male sterility (Brar and Khush 1997). The distinct, wild relatives rice species, Oryza nivara and $O$. rufipogon contain AA genome with 24 chromosomes recognized as a direct progenitor of cultivated rice (O. sativa L.) (Khush 1997). Molecular phylogenetic studies have confirmed that $O$. nivara and $O$. rufipogon are the closest wild relatives of $O$. sativa, but have not resolved reliably the relationships among the three species (Park et al. 2003, Zhu and Ge 2005). The Indo-Gangetic region (IGR) is one of the most intensively farmed zones of the world is endowed with a great diversity of wild rice growing in its natural habitats (Sharma et al. 2000, Thakur and Pandey 2009). In recent years, a considerable amount of information about the genetic structure within and among natural populations of $O$. rufipogon and $O$. nivara has been obtained (Zhou et al. 2008), but O. rufipogon and O. nivara germplasm present in eastern IGP is not well characterized. The aim of the present study was to assess the extent of variability, genetic diversity within a collection of wild rice accessions to aid in introgression and manipulation of the required traits in cultivated rice breeding programme.

\footnotetext{
*Author for correspondence: <pksbhu@gmail.com>. ${ }^{1}$ National Research Centre on Plant Biotechnology,
} Indian Agriculture Research Institute, New Delhi-110012, India. 


\section{Materials and Methods}

Panicles of 35 wild rice germplasm were collected from natural habitat of Eastern IndoGangetic region of India during kharif 2009 (Table 1) and their seeds were multiplied in kharif 2010. The accessions were evaluated at Agricultural Research Farm, Banaras Hindu University, India in a complete randomized block design during main crop season kharif 2011. Twenty five days old single seedlings were transplanted in small separate plot with $20 \mathrm{~cm}$ apart between row and $15 \mathrm{~cm}$ within row. The recommended packages of practices were adopted to raise a good crop.

The observations were recorded 14 quantitative traits viz. days to $50 \%$ flowering, days to maturity, leaf length, leaf width, plant height, panicle length, effective tillers per plant, filled grain per panicle, total number of grains per panicle, fertility percentage, test weight, kernel length, kernel breadth and grain yield per plant. The panicles of accessions showing shattering characteristics were observed daily and filled grains were plucked one by one 1 - 2 days before shattering and stored.

The data were analyzed for variability as per procedure given by Panse and Sukhatme (1985). The genotypic and phenotypic coefficients of variability were worked out as per Burton and De Vane (1953); heritability and genetic advance were estimated procedure by Allard (1960). Mahalanobis $\mathrm{D}^{2}$ statistic (1936) used to measure the genetic divergence. Principle component analysis (PCA) had been used to determine the optimum number of clusters, to complement cluster analysis and to investigate patterns of genetic diversity.

\section{Results and Discussion}

The analysis of variance revealed highly significant difference among the germplasm accessions for all the traits (Table 2) indicating a large amount of variability was present in the material for effective selection of the accessions. Result showed that the magnitude of PCV was higher for yield and yield traits but the difference is very less indicates the presence of environmental influence to some degree in the phenotypic expression of the traits. Similar result was reported by Subudhi et al. (2011). The highest estimate of PCV and GCV were observed for filled grains per panicle (56.21 and 55.39) followed by total grains per panicle (42.07 and 40.86) and grain yield per plant (28.51 and 27.60), and lowest in days to maturity (4.52 and 4.41) followed by days to $50 \%$ flowering (5.41 and 5.26). Moderate value was observed in total number of tillers per plant (24.35 and 22.19), spikelet fertility (20.69 and 20.31), test weight (16.63 and 16.41) and kernel breadth (16.28 and 16.07). Similarly, Anjaneyulu et al. (2010) studied on 50 germplasm lines of rice revealed that high PCV and GCV were recorded for number of grains per panicle, fertility percentage and grain yield per plant. The estimate of heritability was high for kernel breadth (97.46\%), test weight $(97.40 \%)$ and filled grains per panicle $(97.10 \%)$ due to genetic causes rather only by environmental effects. High heritability does not always indicate high genetic gain; heritability coupled with high genetic advance should be used in predicting the ultimate effect for selecting superior varieties. High heritability coupled with high genetic advance as per cent of mean were observed for filled grains per panicle (97.10\% and 112.46), total number of grains per panicle (94.30\% and 81.74$)$ and grain yield per plant (93.70\% and 55.03), while high heritability coupled with low genetic advance as per cent mean were observed in days to maturity (95.50\% and 8.89), days to 50\% flowering (94.60\% and 10.55) and kernel length (93.20\% and 12.31).

Thirty five accessions were grouped into six clusters based on 14 traits presented in Table 3 . The cluster III contained the highest 12 accessions followed by clusters I and IV comprised 11 and 7 accessions, respectively. While clusters II and VI have two accessions each, and cluster V was 


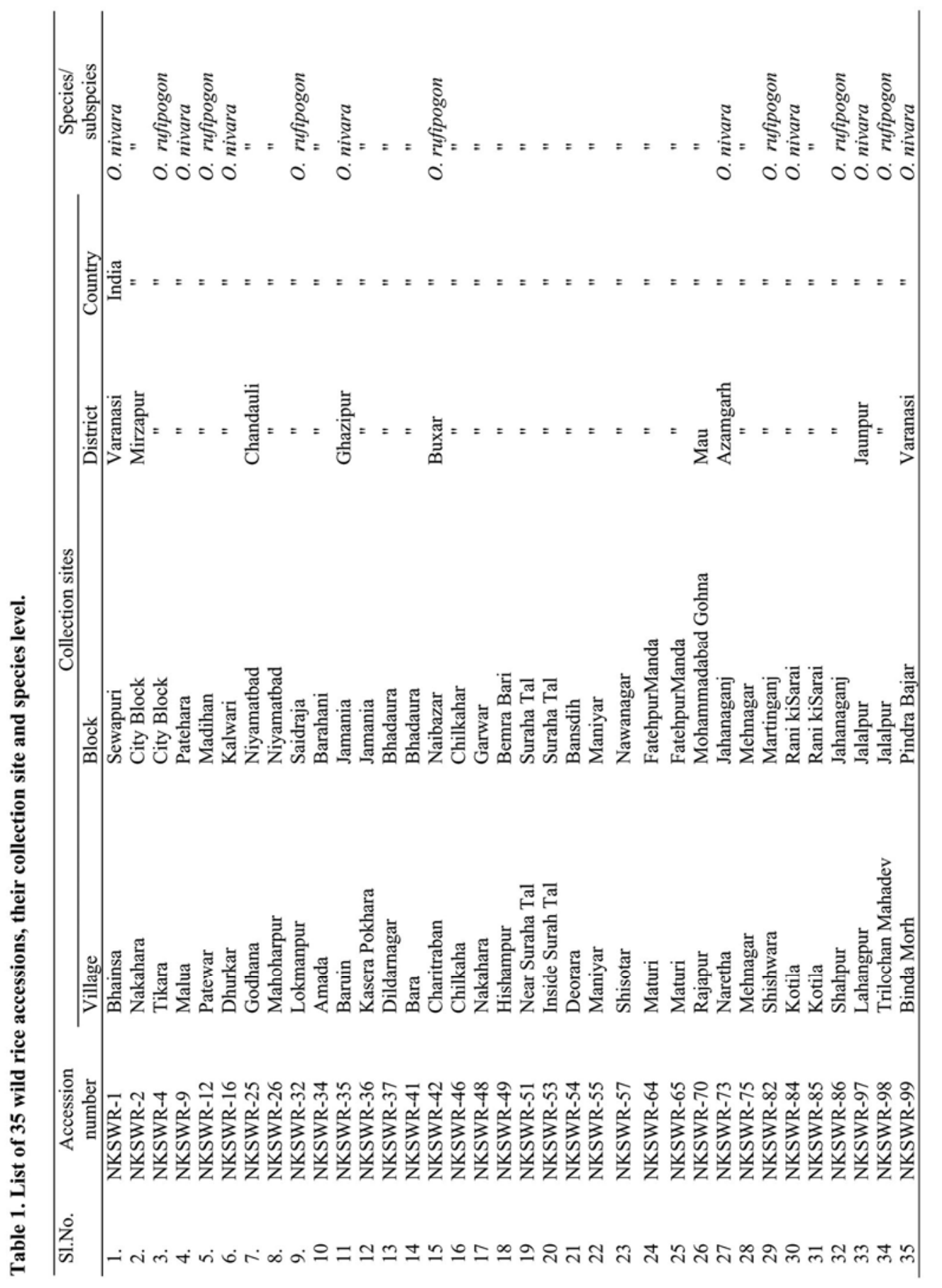




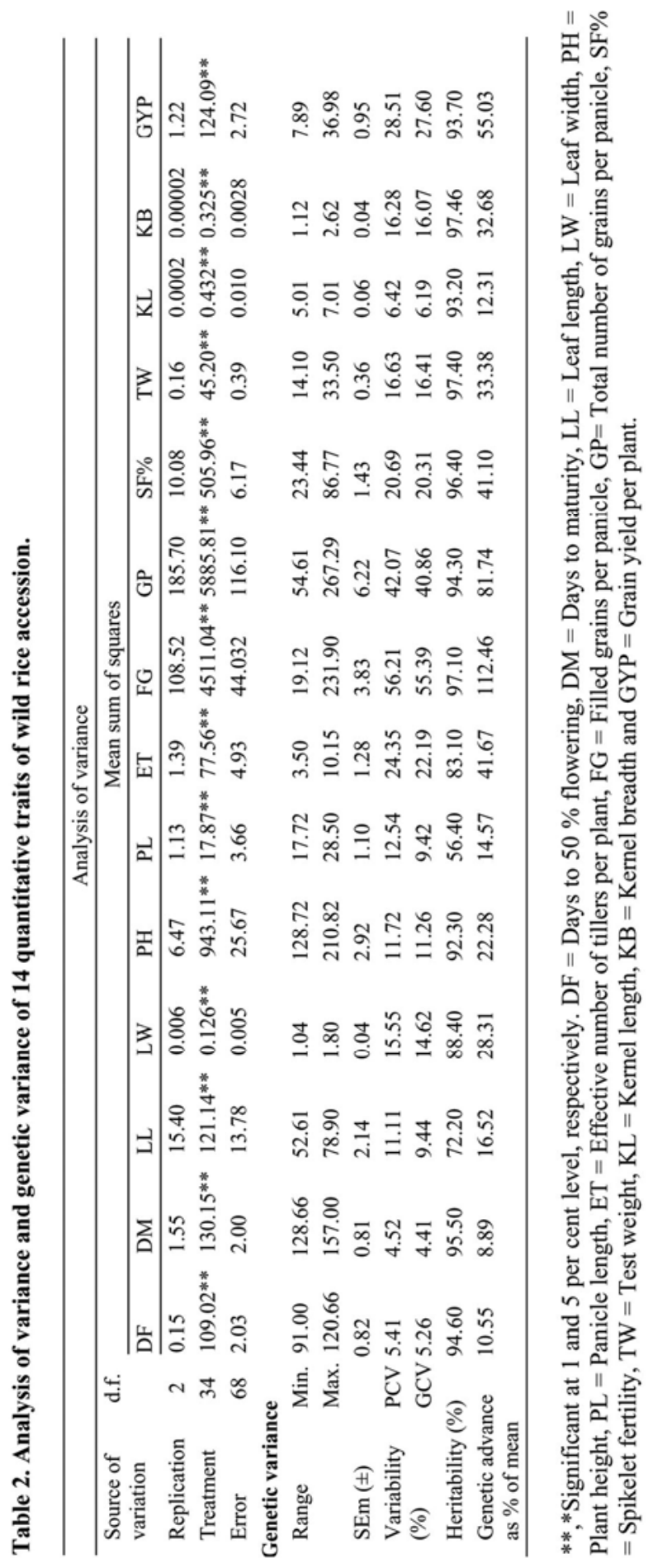


monogenotypic which maintain their distinct identity falling in separate clusters. The clustering pattern indicated wide diversity between different groups of accessions. Accessions included in a particular cluster indicated their close relationship among themselves as compared to the other clusters. Therefore, it could be expected that accessions within a cluster were less genetically different with each other, and were diverse from the accessions belonging to other clusters. Sohrabi et al. (2012) clustered 35 upland rice into six clusters, cluster III contains 27 accessions and clusters I, II, IV and V comprised 6, 10, 2 and 4 accessions, respectively, and cluster VI was monogenic. The intra- and inter-cluster distances among six clusters is presented in Table 4 . The maximum intra-cluster distance was observed for the cluster VI (37.37) followed by cluster IV (24.66) and cluster II (24.21). The maximum inter-cluster distance was observed between clusters $\mathrm{V}$ and VI (77.03) indicated the accessions would be helpful for accumulation of favorable genes in transgressive segregation breeding in rice. The next two diverse clusters were II and V (72.51)

Table 3. Grouping of 35 wild rice accessions into six clusters.

\begin{tabular}{llc}
\hline Clusters & \multicolumn{1}{c}{ Accession } & Number \\
\hline I & NKSWR-2, NKSWR-37, NKSWR-42, NKSWR-86, & 11 \\
& NKSWR-9, NKSWR-41, NKSWR-73, NKSWR-25, & \\
II & NKSWR-85, NKSWR-55, NKSWR-99 & 2 \\
III & NKSWR-26, NKSWR-54 & 12 \\
& NKSWR-12, NKSWR-36, NKSWR-4, NKSWR-97, & \\
& NKSWR-34, NKSWR-35, NKSWR-49, NKSWR-32, & \\
IV & NKSWR-1, NKSWR-46, NKSWR-82, NKSWR-84 & 7 \\
& NKSWR-16, NKSWR-70, NKSWR-98, NKSWR-64, & \\
V & NKSWR-75, NKSWR-51, NKSWR-57 & 1 \\
VI & NKSWR-48 & 2 \\
\hline
\end{tabular}

Table 4. Average intra- and inter-cluster distances among six clusters.

\begin{tabular}{lcccccc}
\hline Cluster & I & II & III & IV & V & VI \\
\hline I & 16.81 & 30.99 & 23.80 & 27.75 & 52.75 & 54.34 \\
II & & 24.21 & 41.33 & 41.85 & 72.51 & 63.04 \\
III & & & 19.22 & 35.85 & 50.82 & 49.61 \\
IV & & & & 24.66 & 46.94 & 62.36 \\
V & & & & & 0.00 & 77.03 \\
VI & & & & & & 37.37 \\
\hline
\end{tabular}

Figs in diagonal indicates intra-cluster distance.

followed by clusters II and VI (63.04). Greater the distance between two clusters, wider the expected genetic distance between them. The genetic distance between the parents largely governs the variability spectrum generated in the segregating generation. Therefore, diverse accessions could be used in breeding programme for improvement of yield and yield related traits. Cluster means (Table 5) indicated that there existed considerable differences in the mean values of different traits. The extreme mean values of the traits were observed to fall in different clusters. The clusters $\mathrm{V}$ exhibited highest and lowest mean values for many traits. The highest mean values for leaf width, plant height, panicle length, filled grain per panicle, number of 


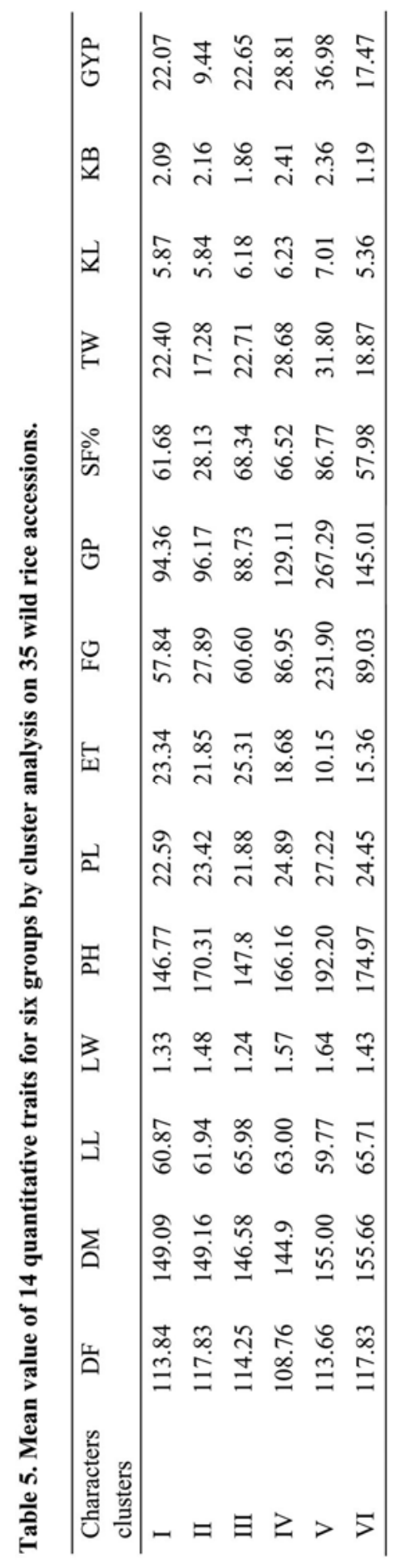


total grain per panicle, spikelet fertility test weight, kernel length, and yield per plant, and lowest mean for leaf length and number of effective tillers per plant were found in cluster V. Cluster III has the highest mean values for number of effective tillers per plant and lowest for leaf width, panicle length and total grains per panicle. Similarly cluster II exhibited highest mean values for days to flowering and lowest for filled grains per panicle, spikelet fertility, test weight and grain yield per plant, while cluster VI also exhibited highest mean value for days to flowering and lowest for kernel length and kernel breadth. Thus, the genotypes in clusters II, III and V seem to be quite promising for many of the traits under study. Singh et al. (2011) reported that highest mean values for days to maturity, plant height, total number of tillers per plant and panicle length and lowest mean values for test weight and kernel length.

PCA approximately confirmed the cluster analysis for distant accession, NKSWR-48, and it was placed alone in cluster V. The based on PCA value, the first four principal components accounted $76.77 \%$ for total variation of all morphological traits. The analysis of Eigen vectors indicated the information of morphological traits for percentage of variation to the first four principal components, which were 35.13, 19.98, 12.98 and 8.68\%, respectively (Table 6). Similarly, Lasalita-Zapico et al. (2010) computed $82.70 \%$ of total variation among 32 upland rice varieties, $66.9 \%$ variation for PC1 and $15.87 \%$ for PC2, and Rajiv et al. (2010) reported the first two principal components accounting for $82.1 \%$ of total variation in control and $68.6 \%$ in the stress-induced genotypes.

Table 6. Eigen vectors and Eigen values of the first four principal components.

\begin{tabular}{lcccc}
\hline Variable & PC 1 & PC 2 & PC & PC 4 \\
\hline DF & 0.09 & 0.06 & 0.41 & -0.15 \\
DM & -0.11 & -0.05 & 0.54 & 0.34 \\
LL & 0.19 & 0.31 & -0.03 & -0.39 \\
LW & -0.28 & -0.36 & -0.08 & -0.11 \\
PH & -0.28 & -0.36 & 0.01 & 0.03 \\
PL & -0.30 & -0.29 & 0.11 & 0.10 \\
ET & 0.24 & 0.28 & 0.01 & 0.44 \\
FG & -0.38 & 0.10 & 0.07 & -0.19 \\
GP & 0.26 & -0.36 & -0.04 & 0.17 \\
SF\% & -0.32 & 0.24 & -0.11 & -0.18 \\
TW & -0.32 & 0.13 & -0.21 & -0.15 \\
KL & -0.25 & 0.17 & -0.04 & 0.43 \\
KB & -0.13 & -0.14 & -0.42 & 0.12 \\
GYP & -0.32 & 0.16 & 0.27 & 0.16 \\
Eigen value & 5.62 & 3.19 & 2.08 & 1.39 \\
Variance (\%) & 35.13 & 19.98 & 12.98 & 8.68 \\
Cumulative variance (\%) & 35.13 & 55.11 & 68.09 & 76.77 \\
\hline
\end{tabular}

The cluster I could be hybridized with clusters V and VI to achieve a wide spectrum of variation among the segregates. Principal component analysis indicated $76.77 \%$ of the total variation showed by first four principal components. PCA and cluster analysis complemented each other with some slight inconsistencies in terms of cluster composition. The separation and selection of varieties based on high heritability of traits make it easy for breeders to exploit their knowledge and skill in transgressive breeding programme. While many researchers agreed with high heritability alone does not effective but high heritability along with high genetic advance 
would be more effective for selecting superior genotypes. In this experiment, filled grains per panicle, total number of grains per panicle and grain yield per plant had high heritability with high genetic advance, which suggested that utilization of these traits could improve the cultivate rice genotype by hybridization and selection of desirable segregants. Therefore, selections of diverse accessions combine with desirable traits are to be effective in accumulation of favorable genes for bringing together into the common genetic background of cultivated indica rice Oryza sativa L.

\section{Acknowledgement}

Authors are thankful to the colleagues of the Department of Biotechnology, New Delhi, Government of India and Ministry of Agriculture, U.P. Government, R.K.V.Y. for financial support (Grant No. 07/473 and P-26/100). Invaluable help rendered by Sri Vivek Singh and Sri O. P. Singh during the collection of wild rice samples from the remote villages of Eastern IndoGangetic region of India is gratefully acknowledged.

\section{References}

Allard RW 1960. Principles of Plant Breeding. John Wiley and Sons Inc. London. pp. 83-108.

Anjaneyulu M, Reddy DR and Reddy KHP 2010. Genetic variability, heritability and genetic advance in rice (Oryza sativa L.). Res. on Crops 11(2): 415-416.

Brar DS and Khush GS 1997. Alien gene introgression in rice. Plant Mol. Biol. 35: 35-47.

Burton GW and De-Vane EH 1953. Estimating heritability in tall fescue, Festuca arundinaceae from replicated clonal material. Agron. J. 45: 578-581.

Khush GS 1997. Origin, dispersal, cultivation and variation of rice. Plant Mol. Biol. 35: 25-34.

Lasalita-Zapico FC, Namocatcat JA and Carino-Turner JL 2010. Genetic diversity analysis of traditional upland rice cultivars in Kihan, Malapatan, Sarangani Province, Philippines using morphometric markers. Philip. J. Sci. 139(2): 177-180.

Mahalanobis PC 1936. On the generalized distance in statistics. Proceedings of the National Institute of Sciences of India. pp. 12-49.

Panse VG and Sukhatme PV 1985. Statical methods for Agricultural workers. $4^{\text {th }}$ ed. ICAR, New Delhi.

Park KC, Kim NH, Cho YS, Kang KH and Kim NS 2003. Genetic variation of AA genome Oryza species measured by MITE-AFLP. TAG 107: 203-209.

Rajiv S, Thivendran P and Deivanai S 2010. Genetic divergence of rice on some morphological and physichemical responces to drought stress. Pertinaka J. 32(2): 315-328.

Sharma SD, Tripathy S and Biswal J 2000. Origine of Oryza sativa and its ecotypes. Enfield, N.H., USA: Science and Publications. pp. 349-369.

Singh AK, Singh PK and Rao M 2011. Diversity analysis in rice under rainfed condition. Ann. Pl. Soil Res. 13(1): 58-61.

Sohrabi M, Rafii MY, Hanafi MM, Siti Nor Akmar A and Latif MA 2012. Genetic diversity of upland rice germplasm in malaysia based on quantitative traits. The Scientific World J. 416291: 1- 9.

Subudhi HN, Das S, Swain D and Singh ON 2011. Variability, correlation and path analysis for quality characters in rice. Oryza 48(4): 319-323.

Thakur AP and Pandey S 2009. $21^{\text {st }}$ Century India: View and Vision. Global Vision Publishing House, New Delhi. pp. 97.

Zhou HF, Zheng XM, Wei RX, Second G, Vaughan DA, Ge S 2008. Contrasting population genetic structure and gene flow between Oryza rufipogon and Oryza nivara. TAG 117: 1181-1189.

Zhu QH and Ge S 2005. Phylogenetic relationships among A-genome species of the genus Oryza revealed by intron sequences of four nuclear genes. New Phytologist 167: 249-265.

(Manuscript received on 11 June, 2013; revised on 10 August, 2014) 